\title{
Los medios, el espectador y la narración: Poderes sutiles.
}

\section{The media, the spectator and the narrative: Subtle powers.}

DOI: $10.32870 /$ sincronia.axxv.n80.10b21

\author{
Sergio Carlos Ramírez Amador \\ Universidad de Guadalajara (MÉXICO) \\ CE: sergiocramireza@gmail.com / ID ORCID: 0000-0002-4007-4026
}

Esta obra está bajo una Licencia Creative Commons Atribución-NoComercial 4.0 Internacional

Recibido: 10/03/2021

Revisado: 04/05/2021

Aprobado: 17/06/2021

\section{RESUMEN}

Desde la proliferación de los medios masivos de comunicación la sociedad ha experimentado cambios importantes. Uno de ellos en materia de poder. En este ensayo analizo las relaciones de poder entre los medios masivos de comunicación y sus espectadores, así como sus mecanismos y consecuencias. Sostengo que este mecanismo es la narración, entendida como una forma de selección deliberada de información con el fin de dotar de sentimientos estéticos los sucesos en el mundo. Esta manipulación de la realidad genera una relación de poder en la medida en que el ciudadano no tiene otras formas de conocer realidades sociales complejas, generando un monopolio de la información, información que puede manipularse tanto en su contenido (hechos) y su forma (narración) para hacer ver al espectador algo que no siempre es el caso. Esto generaría cambios en la opinión pública que puede ser fácilmente instrumentalizada.

Palabras claves: Poder. Medios. Política. Estética.

\section{ABSTRACT}

Since the proliferation of the mass media, society has experienced drastical changes, one of them in regards of power. In this essay I analize the power relationships between the mass media and their spectators, as well as their mechanisms and consecuences. I sustain that this 
mechanism is the narrative understood as a way of deliberately choosing information with the purpose to provide aesthetic feelings to the events on the world. This manipulation of reality generates a power relation as far as the citizen lacks alternative ways of knowing complex social realities, generating an information monopoly, information that can be manipulated both in its content (facts) and in its form (narrative) to show the spectator something that is not always the case. This would generate changes in public opinion which could be easily instrumentalized.

Keywords: Power. Media. Politics. Aesthetics.

\section{Los medios, el espectador y la narración: Sus sutiles poderes.}

El hombre del siglo XXI se muestra ante una época peculiar. A pesar de sufrir de menos carencias, parece siempre necesitar algo más. Con los movimientos del siglo y sus avances tecnológicos la circunstancia del común de los individuos se ha vestido en nuevos colores. No solo la brecha entre sabios e ignorantes se acorta, sino que las potencias del hombre se expanden. El cielo ya no es el límite, sino las estrellas. Naturalmente, la vida en esta sociedad de altas velocidades modifica las costumbres de cada cultura. El ciudadano modifica su catálogo de ideas con más regularidad que en antaño.

Los cambios del siglo no son solo materiales, son también culturales. De necesidad nuevas relaciones de poder emergen. En este ensayo se pretende examinar una relación de poder exclusiva de esta época: la de los medios masivos de comunicación y el individuo. Pretendo que tú, querido lector, me acompañes en este viaje en el que, de forma abstracta, estudiaremos cómo es que se ha dado esta relación, cuál es su mecanismo, sus condiciones de posibilidad y, por tanto, sus consecuencias. Para esto, es menester empezar por el fundamento que sostiene esta relación tan peculiar que, sostengo, no es otro más que la narratividad de la realidad.

Este ensayo lo dividiré en tres apartados: en uno, de la mano de Castells, analizaré el tipo de poder que, sostengo, tienen los medios de comunicación; en otro, de la mano de Ortega y Gasset, analizaré las condiciones de posibilidad de tal poder que, sostengo, se encuentra en el individuo del 
siglo XXI; por último, de la mano de Aristóteles, analizaré el mecanismo por el cual este poder se manifiesta que, sostengo, es por medio de las narraciones. Sin más, comencemos.

Una inspección preliminar

La representación, suele decirse, es el pilar de la democracia contemporánea. A pesar de su necesidad, no parece quedar del todo claro qué significa exactamente. Esto alza una pregunta: ¿qué es representar? Tomar esta pregunta, así como tal no servirá de mucho, debe reformularse. Si representar necesariamente implica un representado y un representante. ¿Quién es el que representa?, ¿a quién se representa? En el desarrollo de estas dos preguntas se encuentra la respuesta a la primera.

En una democracia partidista, el representante se manifiesta por medio del partido o candidato que sostiene ideas e intereses. A este partido se le asigna poder legislativo (limitado por otros partidos) para velar por ideales e intereses específicos. Desde iniciativas de ley hasta voto en temas relevantes. Esta es la razón de existir del partido. Por otro lado, el representado se manifiesta en el individuo que elige a tales partidos o candidatos.

Lo característico del individuo en este tipo de representación es que tiene una cosmovisión, un sistema de valores, de creencias, intereses. Se ha de considerar algo clave: el individuo elige, sí, pero ¿por qué elige lo que elige? Está claro que las ideas de cada cual, es decir, la cosmovisión es lo que motiva. Pero ¿cómo es que se cosmovisión? Los individuos al vagar por el mundo se encuentran con su circunstancia. Las fuerzas internas de un ser biológico se contraponen a las fuerzas de su ambiente. Los individuos nacen en un lugar, viven ciertas experiencias, respirando aires autóctonos; crean nexos con otras personas, unen sus vidas. Ultimadamente, buscan encontrar significado al mundo que los rodea.

El resultado de esta faena es un conjunto de convicciones sobre la realidad: “Antes de hacer algo, tiene cada hombre que decidir, por su cuenta y riesgo, lo que va a hacer. Pero esta decisión es imposible si el hombre no posee algunas convicciones sobre lo que son las cosas en su derredor, los otros hombres, él mismo. Solo en vista de ellas puede preferir una acción a otra, puede, en suma, vivir." (Ortega, 1984, p. 29). Es un hecho que las cosas no hablan por sí mismas, se necesita 
encuadrar la realidad en un marco de ideas que la dote de sentido, este es el principio que abre a la hermenéutica, todo individuo interpreta, y toda interpretación requiere una cosmovisión.

A veces la línea entre cosmovisión e identidad es muy delgada, a veces uno es sus ideas. Los espíritus curiosos buscarán forjarse su propia cosmovisión, pero es inevitable que su cosmovisión se vea influenciada por otras cosmovisiones, por lo general heredadas de la cultura en la que se nació. Castells dirá "La construcción de las identidades utiliza materiales de la historia, la geografía, la biología, las instituciones productivas y reproductivas, la memoria colectiva y las fantasías personales, los aparatos de poder y las revelaciones religiosas" (Castells, 2001, p. 29).

Elaborará en este concepto haciendo la distinción entre diversas formas de identidad entre ellas la que nos compete: "Identidad proyecto: cuando los actores sociales, basándose en los materiales culturales de qué disponen, construyen una nueva identidad que redefine su posición en la sociedad y, al hacerlo, buscan la transformación de toda la estructura social" (Castells, 2001, 2001, p. 30).

Teniendo esto en cuenta: el individuo al decidir cuál candidato o partido le representa ¿qué es lo que busca exactamente? Por supuesto, un partido que esté en concordancia con aquello que el individuo autónomamente sostiene, su identidad proyecto. El individuo confía en que sus intereses estén lo suficientemente alineados como para que la acción de estos representantes en el poder legislativo no afecte de manera negativa a las percepciones del individuo. En otras palabras, las cosmovisiones han de ser compatibles.

Esto pareciera sugerir que el votante analiza cuidadosamente a su realidad y a sus representantes. Mas no caigamos en esta trampa. Si bien, este es el caso de algunos, suele suceder comúnmente que los votantes eligen, más bien, irracionalmente. Esto porque la cosmovisión del individuo no tiene por qué ser sistemática o racional. Como Caplan (2006) señalará: los votantes eligen en función de lo que ellos perciben como lo mejor, más nunca se detienen a analizar si genuinamente esto se sostiene. Entonces la percepción es la clave del voto y justamente esto, la percepción, será el objeto de los medios de comunicación. 
La cosmovisión del individuo es clave a la hora de la toma de decisiones. Cuando el individuo elige su partido tiende a votar por las opciones que el percibe como la mejor para todos, tal como indica Caplan (2006). Mas esta percepción tiene que estar fundada en una cosmovisión, es decir, en una serie de creencias acerca de cómo es el mundo. Ciertamente estas percepciones no tienen por qué ser verdaderas, basta con que sean creencias, como diría Ortega:

Las creencias son lo que verdaderamente constituye el estado el hombre. Las he llamado "repertorio" para indicar que la pluralidad de creencia en que un hombre, un pueblo o una época está no posee nunca una articulación plenamente lógica, es decir, que no forma un sistema de ideas, como lo es o aspira serlo, una filosofía. (Ortega, 1984, p. 30).

¿Qué significa esto en el la política? El representante sostendrá ciertas ideas generales con las cuales acercarse a los individuos y unirlos bajo un mismo grupo. Estas ideas, naturalmente, tienen que apelar a los sucesos que los votantes perciben como urgentes o necesarios. De otro modo se correría el riesgo de no tener apoyo popular y perder ante otro representante que sí apele a las nociones de los votantes tal como concluye Caplan (2006).

El representante sabe que los temas políticos (de presupuesto, de ley, etc.) son complejos y no del interés popular. Por tanto, si este político tratase de acercarse a sus votantes únicamente con justificaciones racionales, los votantes no prestarían atención. Esta estrategia política tiende a fallar pues el cerebro no está separado de las emociones y, en muchas ocasiones, estas priman por sobre lo valido o lo razonable. Esta es la tesis central del libro de The political brain (Westen, 2007).

Por este motivo, el representante se ve en la necesidad de utilizar otras estrategias retóricas para acercarse a los representados (estrategias que analizaremos más adelante), lo cual implica descuidar el aspecto racional de su cosmovisión para hacerla accesible al público. La consecuencia lógica de estos problemas es clara. el representante tiene que narrar una postura para hacerla persuasiva. ¿Cuál es el problema de esto? La narración no tiene por qué ser ni verdadera ni sus ideas efectivas, solo necesitan estar bien narradas para poder entrar en las cosmovisiones populares y pasar a ser opinión pública. 


\section{Un poder sutil}

Las formas de transmitir ideas han cambiado. Como veremos más adelante, este cambio tiene profundas consecuencias en el tejido social y en la forma de hacer política. Desde siempre se han transmitido ideas por medio de la familia, la escuela, la comunidad, el mercado, la iglesia; los nexos sociales. De a poco estos factores (que no son otra cosa que la circunstancia del individuo) terminan por influenciar la cosmovisión del individuo. De la adopción de estas ideas es de donde nace una identidad.

Cuando se trata de política, las ideas son protagonistas sutiles, estas se encuentran de fondo a todo movimiento político, más allá de los líderes carismáticos. La identidad política es una extensión de la identidad personal, en términos de Castells, es una identidad proyecto. Esta sociedad tecnológicamente avanzada ¿qué nuevos mecanismos posee para producir y reproducir ideas? Podemos decir noticieros, reportajes, programas de opinión, películas, cápsulas de radio, artículos web; al final todo se reduce a lo mismo: medios de comunicación.

Es un hecho que esta novedad ha iluminado la mente de muchos que en antaño carecían de acceso a todo tipo de información, mas este hecho no nos libra del riesgo que estos implican. El problema es hondo y requiere atención. Por un lado, la naturaleza del medio impacta al mensaje, por otro, estos medios tienen dueños. A estos últimos los llamamos la industria del entretenimiento.

Y es apropiado llamarles industria del entretenimiento, pues la línea que separa información y entretenimiento no existe en una época en donde todo (desde la educación hasta los noticieros) ha de ser entretenido, a riesgo de ser desechado si no se es. Tal fenómeno fue llamado por Postman "la era del mundo del espectáculo" (Postman, 2001, p. 68). Estos medios no transmiten solo información, transmiten mensajes. La información es el contenido del mensaje, mas esta información se tiene que transmitir de una manera (forma).

Todo mensaje, en cuanto información empaquetada, implica una materia y una forma, un qué y un cómo. Es común creer que el qué y el cómo son cosas distintas, que todo medio es apto 
para todo mensaje, mas este no es el caso. Recordando a Postman (2001) y a McLuhan (1994): Los medios, al ser la forma, condicionan los contenidos que se pueden transmitir, es decir "el medio es el mensaje" (McLuhan, 1994, p. 29). Hay ciertos medios que favorecen ciertos tipos de contenidos, "no se puede utilizar el humo para hacer filosofía. Su forma excluye su contenido." (Postman, 2001, p. 11)

Ciertamente el siglo XXI está dominado por lo audiovisual. El medio especifico, desde la televisión hasta el teléfono celular, tiende a la masificación de imágenes y a su veloz distribución. Este ritmo acelerado, de cambio de una imagen por otra, en cortos tiempos, deja poco para la reflexión de lo que se acaba de consumir. Entonces ¿cómo es que se genera una impresión duradera en estos medios? Por medio de las sensaciones estéticas. Estos medios favorecen el sensacionalismo pues este, al enfocarse en emociones, tiene un impacto tanto o más significativo que los mismos contenidos del mensaje. No es sorpresa que las series, las telenovelas y las películas sean lo que más se consume en estos medios.

El humano es emocional, sin duda. Cuando recordamos este hecho, las consecuencias de lo anterior resaltan. Los medios masivos de comunicación muestran realidades descontextualizadas y las muestran con tintes emocionales. Se ha demostrado que el uso de música, imágenes y eslóganes en campañas políticas tienen tanto o hasta más impacto en el éxito de la campaña que sus mismos contenidos (Westen, 2007).

Este hecho explica el por qué la estrategia preferida del político en estos tiempos sea el cuidado de la imagen proyectada al público, seleccionando cuidadosamente a asesores de imagen que le permitan mostrar su cara más favorable, en este caso, la imagen será más importante que la pertinencia. Como dirá Postman:

En el desplazamiento de la política de partidos a la política de televisión, se procura la misma meta. No se nos permite saber quién sería mejor como presidente, gobernador o senador, sino quién tiene la imagen que mejor puede alcanzar y calmar la profundidad de nuestro descontento. (2001). 
Como señaló Postman (2001) La radio, la televisión y la internet (este último tiene sus detalles que analizaremos más adelante) han modificado la estructura de transmisión de ideas. La información se otorga al espectador de manera fragmentada, divorciada de su contexto, en grandes cantidades y grandes velocidades. Ciertamente es fácil perderse en un océano de información. El humano, como ya vimos, necesita encuadrar tanta información de alguna forma para poder comprenderla. Esta es la función de las narraciones.

Los medios masivos de comunicación no son esferas desinteresadas. Las historias de moda proponen valores de moda, sus héroes reflejan un ideal de hombre nuevo, los conflictos en las historias mutan con cada nuevo movimiento social. Si estas ideas flotasen en un mismo espacio, con igualdad de difusión, no existiría problema alguno pues estas ideas estarían obligadas a discutirse, a depurarse. El problema deviene cuando esta industria (incluyendo los medios) se monopolizan, pues, como veremos, la centralización de los medios implica una centralización de poder.

¿Por qué sostengo que es un monopolio? Quizás la palabra más adecuada sería oligopolio pues es cierto que no en todo medio de comunicación es controlado por una sola entidad. Pero es también cierto que los medios no son enteramente democráticos pues no todo aquel que quiera tiene la capacidad de difundir sus ideas al gran público. En estos medios podemos ver un número limitado de cosmovisiones que pueden o no estar en conflicto. Es fácil perderse en una falsa dicotomía cuando solo hay dos o tres grandes dueños de las discusiones. Es a este fenómeno al que me refiero cuando hablo de oligopolio en los medios.

Dicho oligopolio sustenta una posición especial entre las otras acumulaciones de poder. Para poder entender esta posición es necesario entender bajo qué paradigma operan estos medios, que no es otro que una revolución en la forma de transmitir información. Castells identificará una de las características principales del paradigma que esta revolución tecnológica significó: "la primera característica del nuevo paradigma es que la información es su materia prima: son tecnologías para actuar sobre la información, no solo información para actuar sobre la tecnología, como era el caso en las revoluciones tecnológicas previas" (Castells, 1998, p. 105). 
Siguiendo a Bostrom (1983), las fuentes de donde obtenemos la información sobre el ambiente, información con la que nos haremos una percepción del mundo, son decisivas a la hora de tomar una actitud respecto a algún suceso del ambiente. Según este, las fuentes se miden en función de su credibilidad, concepto que se le atribuye a la fuente previo a la recepción de cualquier información. La credibilidad se divide en confianza y expertise. La primera consiste en la creencia de que esta fuente no tiene motivos para mentir al espectador y la segunda en la creencia de que estas fuentes están los suficientemente cualificadas para hablar del tema.

Estas dos cualidades describen perfectamente el percibido rol social de los medios de comunicación. Se confía en ellos para recibir información de las realidades que no podemos conocer, tanto por su aparente neutralidad como por las personalidades que suelen exponer estas perspectivas, mas, recordemos que las fuentes no son un son un puente entre el sujeto y su ambiente, más bien, son interpretes del ambiente. (Bostrom, 1983).

Llamarlos medios de comunicación no sería del todo correcto, pues sus tecnologías no son simples puentes entre la realidad y el espectador, sino que son productoras de mensajes, siendo la información la materia prima a procesar, empaquetar y distribuir. Los medios masivos de comunicación producen y reproducen narrativas (discursos) con la peculiaridad de situarse en la realidad. Por citar unos ejemplos: los noticieros informan sobre ciertos hechos, se discuten ciertos temas, se revelan datos de determinadas personas (datos que afectan la imagen de los involucrados), la gente no tarda en sospechar.

Los medios de comunicación tienen el poder de elegir cómo representar la realidad, en otras palabras, producen realidad. En consecuencia, favorecen o desfavorecen algunas interpretaciones de la realidad, y ¿cómo dudar de ellos? Pues los noticieros muestran evidencias: imágenes de la realidad, fotografías comprometedoras, documentos firmados. Cierto es que sus evidencias parecen convincentes, sus historias coherentes y sus motivos justos.

Mas recordemos el peso que tiene la credibilidad en los medios de comunicación, pues la credibilidad se le atribuye al medio antes de recibir el mensaje. Esto tiene una consecuencia y es que la audiencia tiende a colocar por encima de la calidad o legitimidad de la evidencia la 
credibilidad de la fuente (Bostrom, 1983). La credibilidad es la columna vertebral del poder de los medios de comunicación

El trabajo de estos medios no es el de la investigación per se, sino el de la manufacturación de un producto hecho de información, atractivo y de fácil consumo. Y el sujeto lo ha de consumir con tranquilidad pues ¿cómo dudar? Como ya señalaron Adorno y Horkheimer: esta industria cultural induce un estado de pasividad al espectador pues poco o nada motiva al cuestionamiento de las realidades mostradas, sino a la aceptación de lo ya establecido (Horkheimer \& Adorno, 1998).

Si consideramos que los medios de comunicación tienen dueño, y a eso le añadimos que el individuo común solo puede tener acceso a la información de su ambiente a través de los medios de comunicación, nos encontramos con una estructura de poder. Al adquirir el control de los medios de comunicación, inevitablemente, se adquiere el poder de modificar la opinión pública por medio de narraciones (exploraremos este mecanismo más adelante) que sostienen las cosmovisiones afines a los intereses de esos medios. Sartori hará un señalamiento importante respecto a la opinión pública:

En primer lugar, la opinión pública tiene una ubicación, debe ser colocada: es el conjunto de opiniones que se encuentra en el público o en los públicos. Pero la noción de opinión pública denomina sobre todo opiniones generalizadas del público, opiniones endógenas, las cuales son del público en el sentido de que el público es realmente el sujeto principal. Debemos añadir que una opinión se denomina pública no solo porque es del público, sino también porque implica la res publica, la cosa pública, es decir, argumentos de naturaleza pública: los intereses generales, el bien común, los problemas colectivos. (1998, p. 69).

Los temas políticos no son la excepción, estos también se difunden por medio de narraciones y estas narraciones tienen dueño. Como Sartori señala:

Entonces ¿cómo se constituye una opinión pública autónoma que sea verdaderamente del público? Está claro que esta opinión debe estar expuesta a flujos de informaciones sobre el estado de la cosa pública. Si fuera «sorda», demasiado cerrada y excesivamente 
preconcebida en lo que concierne a la andadura de la res publica, entonces no serviría. Por otra parte, cuanto más se abre y se expone una opinión pública a flujos de información exógenos (que recibe del poder político o de instrumentos de información de masas), más corre el riesgo la opinión del público de convertirse en "hetero-dirigida», como decía Riesman. (1998, p. 70).

Este es el poder que ostentan los medios, el de la opinión pública. Esta se funda ultimadamente en una noción de lo que es el mundo (cosmovisión). El estado del mundo se puede presentar de manera tal que haga parecer que cierto curso de acción es necesario para cambiar tal situación, este es el trabajo de la narración. Quien tenga acceso a las vías por las cuales esta información llega a las masas, tiene acceso de la opinión de estas.

Es en la opinión pública donde ultimadamente el poder se manifiesta. Como afirma Ortega

El mando es el ejercicio normal de la autoridad. El cual se funda siempre en la opinión pública -siempre, hoy como hace diez años, entre los ingleses como entre los botocudos-. Jamás ha mandado nadie en la tierra nutriendo su mando esencialmente de otra cosa que de la opinión pública. (Ortega, 2012, p. 366).

Todo movimiento político o social exitoso necesita de la simpatía y suscripción de las masas, el poder de la opinión pública es clave a todo éxito político, mucho más que la pertinencia de las propuestas o la misma fuerza.

El problema que nace de tal oligopolio es el de una acumulación de poder por parte de grupos privados con intereses privados. No existe garante que obligue a tal oligopolio a ver por el interés común, sino que siempre existe la posibilidad de un interés particular esculpiendo la percepción del espectador. Como dijo Aristóteles: "Las buenas formas de gobierno son aquellas en que una sola persona, unas cuantas o muchas gobiernan con la vista puesta en el interés común; Son viciados los gobiernos que contemplan intereses particulares." (Aristóteles, 1982a, p. 301). 
Ciertamente los medios de comunicación no son gobiernos, pero tienen un poder innegable sobre ellos, pues pueden influenciar gravemente a la base de votantes que apoya o desprecia a cierto grupo o partido. Es un poder de facto.

Esto es evidente en la televisión, el cine y la radio. Pero no lo es tanto en las llamadas redes sociales. En cierta medida, sufren de los mismos males que los medios de comunicación tradicionales, mas, su configuración es más compleja. Estas redes, al ser entidades privadas, se reservan el derecho a regular aquellas interacciones en sus redes que consideren inapropiadas. No es sorpresa que en los términos y condiciones que el usuario acepta al ingresar a estas redes suelan encontrarse con llamadas normas de la comunidad que establecen límites a lo que se puede expresar en esas redes. Esto, por sí solo, ya representa un problema a la libertad de expresión.

Sin embargo, hay una diferencia radical en las redes y los medios tradicionales de comunicación. La red no es unidireccional, es un espacio virtual en donde múltiples individuos comparten algo de sí, sus ideas o sus vidas. Dirá Castells:

Cuando, posteriormente, la tecnología digital permitió empaquetar todo tipo de mensajes, incluido el sonido, las imágenes y los datos, se constituyó una red capaz de comunicar sus nodos sin utilizar centros de control. La universalidad del lenguaje digital y la pura lógica reticular del sistema de comunicación crearon las condiciones tecnológicas para una comunicación horizontal, global. (1998, p. 77).

En sus inicios estas redes constaban de foros de texto especializados en un tema o creados con un sentido de comunidad virtual, es decir, estaban enfocadas en algún tema o interés (tal como se mantiene Reddit en la actualidad). Pero el avance tecnológico pronto posibilitó la transmisión de imágenes y sonido en escalas masivas. Es ahí cuando las redes sociales enfocadas en personalidades alzaron vuelo (tal como Facebook, Twitter e Instagram).

En principio. Una plataforma así es ideal para la discusión pues no hay un control centralizado que decida qué opiniones han de distribuirse, pero este mal no desapareció, simplemente transmutó. Las redes sociales no son utilizadas como plataformas de debate y 
discusión, son utilizadas como una expansión de la imagen personal. Este punto adquiere claridad cuando observamos que el común de los individuos, cuando decide compartir algo, comparte sus fotografías, sus gustos, sus disgustos, sus formas de entretenimiento y, hasta el final, sus opiniones. La red social está diseñada en función de la popularidad, de este concepto se derivan los problemas de las redes como foros de discusión.

Es fácil darse cuenta de esto por la forma en la que tales redes deciden resaltar unas opiniones y enterrar otras (quien más visitas, likes, favoritos, compartidos ostente, más visibilidad adquirirá). Hay quienes pueden vivir de simplemente ser populares en tales redes. Los personajes con mayor popularidad suelen acaparar mucho más de ese espacio virtual que aquel que poco participa de ese juego de la aprobación de las masas. Esto derrota todo motivo intelectual que una red social pudiese tener (salvando grupos especializados que decidan jugar bajo otras reglas) pues la naturaleza de una discusión es mesurada y extensa, implica un esfuerzo para conocer las palabras del otro, así como aquellos supuestos que se encuentran imbuidos en tales opiniones.

Si a esto se sumamos la naturaleza personal (es decir, enfocada en individuos y no en temas) de la red social, el individuo adquiere la habilidad de censurar al otro de su espacio virtual, se torna más fácil el huir de tal conversación (bloqueando al individuo o ridiculizándolo ante la masa) en lugar de explorar sus ideas. La relación de poder se descentraliza en cuanto a la propiedad del foro, pero se vuelve a centralizar en cuanto a la viralidad de la opinión y es evidente que la viralidad no equivale a racionabilidad, hay mucho espacio para la doxa pero poco para la episteme. El problema de la opinión pública planteado por Sartori se mantiene intacto.

Se ha de explorar, antes de pasar a otro tema, otro poder sutil que ostentan las redes, mejor dicho, los dueños de las redes. Estas redes se entregan gratis al individuo común, pero nada es gratis en la vida. ¿Qué clase de provecho tendría sostener una red así? Si se asume que las empresas son privadas con fines de lucro, entonces tiene que ser remunerable económicamente. Realmente el bien que se extrae es información.

Esto no es muy difícil de comprobar, tan se ha que revisar los tipos de permisos que las aplicaciones de redes sociales en los teléfonos celulares exigen. La información se extrae, se 
argumenta, para conocer los hábitos, gustos y preferencias de un individuo, desde donde se prefiere ir a comer hasta las causas políticas que se apoya. Todo esto para entregarle publicidad acorde a dicha persona. Ciertamente el producto que venden las redes son estos datos iy no faltan compradores! Pues ¿qué es más útil para una empresa que el conocimiento de su mercado? Si se conocen las preferencias del individuo, es más fácil manufacturar productos propensos a ser consumidos por ellos.

Ahora recordemos que los medios de comunicación también manufacturan productos con apariencia de realidad (más tarde analizaremos este producto) ¿no les tentaría esta información? La radicalización política por medio de las redes no es una ficción, pues no es muy difícil convencer al moderado mostrándole determinadas realidades avaladas por los medios de comunicación tradicionales. La información como mercancía es un problema. Dejando esto de lado, es obvio que estos problemas tienen dos raíces. Sí, los medios juegan un papel, pero la pasividad del individuo del siglo XXI es la mismísima condición de posibilidad de todos estos problemas ¿Quién es este individuo?

\section{El individuo no es inocente}

Es pertinente fijar la atención en el público de los medios, pues este juega su papel. Es cierto que cada individuo forja su interpretación de la realidad basándose en sus muy íntimas experiencias, pero el hombre que habita este sigo es un hombre distinto. No cargo con el yugo de un señor en tiempos feudales, no sufrió el horror de la esclavitud, vive en una democracia liberal que gravita en torno a sus opiniones. En sistema económico capitalista que cada quince días le provee de placeres, de mercancías exóticas, de estatus; en un mundo de consumo y producción, donde basta dar 9 horas del día para disfrutar de comodidades.

El mundo parece girar en torno al individuo y sus deseos, pues la democracia liberal pone al individuo al centro del juego político, así mismo el sistema económico coloca en su centro al individuo, que con sus intereses mueve mercados, que vota con su dinero a los productos que han 
de sobrevivir. Esto no es una calamidad per se es un progreso en comparación con los feudos o los esclavistas, pero no viene desprovisto de vicio, la libertad fácilmente se torna en arrogancia.

Esta inspección no es nueva, Ortega y Gasset realizó, en su época, un análisis a las consecuencias de esta organización social. Dirá: “Mi tesis es, pues, esta: la perfección misma con que el siglo XIX ha dado una organización a ciertos órdenes de la vida es origen de que las masas beneficiarias no la consideren como organización, sino como naturaleza." (Ortega, 2012, p. 312).

Siguiendo a Ortega (2012), la civilización que el sujeto del siglo XX heredó del sujeto del XIX se estructuró en función de dos elementos: democracia liberal y técnica. Para el desarrollo de estas dos, el sujeto del XIX requirió una ardua disciplina intelectual para conocer los principios de la ciencia que pronto se aplicarían a la técnica. Así mismo, necesitó una introspección profunda de la sociedad, la naturaleza humana, el poder político y la moral para llegar a la conclusión de que todo individuo merece su libertad, así como de una voz en la arena política.

Dicha disciplina solo pudo venir de una necesidad vital de los hombres de aquella época. Las presiones sociales, económicas y políticas le forzaron a disciplinar su mente para poder generar la civilización que los individuos del XX gozarían. Sin embargo, los individuos del XX nacieron ya con esa civilización, como si esta existiese por naturaleza (Ortega, 2012).

Al considerarse como naturaleza, se considera autosustentable, siempre ahí. Gozaron los beneficios de la herencia del XIX sin la misma disciplina intelectual que la hizo posible. Sin esta disciplina la civilización puede fácilmente entrar en crisis. Se desconoce las presiones tanto morales como económicas del pasado que fueron necesarias para que los avances de este siglo fuesen posibles. Al considerar estos avances como naturaleza, el individuo goza sus beneficios sin preocuparse por sus principios, simplificando su cultura e ignorando su historia (Ortega, 2012).

Mas esto es aún más grave. Como señala Ortega (2012), El avance del XIX no fue cualquier avance. EI XIX hizo a todos los hombres iguales, brindó poder a los individuos que en antaño carecían de él, generando la democracia liberal en la que el voto de todo hombre tiene el mismo valor. Por otro lado, la técnica logró que el nivel de vida del individuo promedio subiese considerablemente, abriéndole las puertas a los lugares que antes estaban reservados para elites. El 
individuo del XX, al nacer en esta época, se da cuenta de que no existen restricciones morales ni materiales para acceder a placeres y lugares, entre ellos los campos intelectuales y políticos.

El hombre no encuentra resistencias, el sistema político lo pone en el centro de su quehacer y la técnica le provee de todo lo que desee. Esto hizo del hombre del XX uno arrogante y perezoso, pues no necesita disciplinarse para poder opinar o gozar de placeres. Como afirmará Ortega:

Esto nos lleva a apuntar en el diagrama psicológico del hombre masa dos primeros rasgos. La libre expansión de sus deseos y, por tanto, de su persona y la radical ingratitud hacia cuanto ha hecho posible la facilidad de su existencia. (Ortega, 2012, p. 310).

Esta libre expansión de sus deseos no requiere disciplina o esfuerzo alguno, el hombre puede disfrutar de lo que sea sin tener que rendir cuentas a nadie. Esto es un avance, por su puesto, pero tendrá su consecuencia lógica en el mundo intelectual. Esta consecuencia la llamará Ortega hermetismo intelectual:

Ya sé que muchos de los que me leen no piensan lo mismo que yo. También eso es naturalísimo y confirma mi teorema. Pues, aunque resultase en definitiva errónea mi opinión, siempre quedara el hecho de que muchos de esos lectores discrepantes no han pensado cinco minutos sobre tan compleja materia ¿Cómo van a pensar lo mismo que yo? Pero al creerse con derecho a tener una opinión sobre el asunto sin previo esfuerzo para forjársela, manifiesta su ejemplar pertenencia al modo absurdo de ser hombre que he Ilamado "Masa rebelde". Esto es precisamente tener obliterada, hermética, el alma. En este caso se trata de hermetismo intelectual. La persona se encuentra con un repertorio de ideas dentro de sí, Decide contentarse con ellas y considerarse intelectualmente completa. Al no echar de menos nada fuera de sí, se instala definitivamente en aquel repertorio de ideas" (Ortega, 2012, p. 319)

La inspección de Ortega y Gasset, sostengo, se mantiene casi intacta hoy en día. El individuo da por hecho su democracia y su tecnología pues nació con ellas. Esto lo hace perezoso de necesidad, pues una vida placentera requiere infinitamente menos esfuerzos que en antaño. Esta disminución de 
esfuerzo no es solo física, sino intelectual. Si el individuo necesita saber algo, no hace falta más que tomar un móvil y escribir la pregunta. Como sus preguntas suelen ser mundanas, las respuestas suelen ser simples. El individuo se conforma con esta simplicidad y la extrapola a todo conocimiento, incluyendo el conocimiento de lo político.

Caplan (2006) también tendrá algo que decir sobre este tema. Argumentará que, en cuestiones políticas, el ciudadano suele no solo ser ignorante, sino que directamente irracional. El ciudadano se da cuenta de que sostener ideas o creencias ilusorias no representa ningún costo pues el voto individual difícilmente hará un cambio. De este modo, le es más atractivo al ciudadano sostener aquellas ideas que lo hagan sentir mejor consigo mismo, apoyándose en sus sesgos más que en una cuidadosa reflexión (pues esta sí que requiere esfuerzo y tiempo).

Se da por hecho de que el medio de comunicación le cuenta toda la verdad, pues no tiene razones para dudar de él. Dudar del mundo que a uno rodea requiere esfuerzo, no es deseable. Es más fácil creer a aquellos que se especializan en informarnos sobre lo que sucede en nuestro mundo, asignándole verdad a los hechos por virtud de quien lo dice, no por su correspondencia con la realidad.

Las sociedades democráticas necesitan de participación, es cierto, pero no toda sociedad hace buenas democracias pues los temas políticos requieren cuidado y atención. Los miles de años de literatura política son prueba de lo complejo del entramado de las organizaciones humanas, de cómo recorrimos un duro camino de guerras y tiranos para lograr una relativa paz. Se ha de ser un tipo específico de persona para adoptar una vida democrática, una sociedad radicalmente distinta al del hombre del siglo XXI. Este hombre no necesita cuestionarse su vida democrática, pues vive arropado por ella, cree que esta democracia es autosustentable, que no necesita de ojos atentos, de almas abiertas al dialogo.

La civilización no está ahí, no se sostiene a sí misma. Es artificio y requiere un artista o artesano. Si usted quiere aprovecharse de las ventajas de la civilización, pero no se preocupa usted de sostener la civilización..., se ha fastidiado usted. En un dos por tres se queda usted sin civilización. (Ortega, 2012, p. 334). 
No solo eso, sino que también se necesita un ímpetu altruista en su interpretación de la realidad, carente en generaciones tan individuales. Una democracia, como lo expresó Aristóteles citas pasadas, necesita que sus gobernantes (el pueblo) vean por el interés común, no por el interés privado. Pero ¿cómo pedirle al hombre del siglo XXI que haga tal hazaña? Si su vida entera giró en torno a él, si la información siempre la tuvo en la palma de su mano ¿cómo pedirle dudar?

Tenemos al fuego y a la gasolina. Tenemos la combinación de los medios de comunicación, tan interesados y el individuo, tan desprovisto de dudas. Es inevitable la explosión que tendrá como engendro este hermetismo intelectual.

$\mathrm{Y}$ es que es de esperarse. Los individuos no pueden conocer todas las realidades, las tienen que obtener de medios interesados, no tienen el tiempo para cuestionarlos. Naturalmente que serán fácilmente manipulados, obliterados. La figura que tomará este individuo dejara de ser la de hombre culto en democracia y pasara a ser la de tonto útil a los intereses de los poderes que le facilitan su cómoda existencia.

Es difícil encontrar una sola causa para que este individuo del siglo XXI haya mudado su alma a tal hermetismo. Ni la democracia liberal ni las abundancias solas explican este fenómeno. Sartori ya señaló el cómo es que los medios de comunicación suplantaron la abstracción por la visión, disminuyendo la capacidad del individuo de crear ideas autónomamente (Sartori, 1998). Considero que no se equivoca, pues la facilidad del consumo de un producto audiovisual poco espacio le deja a la lectura que requiere un grado de interpretación, comprensión y abstracción suficiente como para alejar a este individuo perezoso. Pero ciertamente falta algo y creo saber que es.

\section{La narración instrumentalizada}

Se ha indagado en los medios de comunicación, se ha indagado en la audiencia (que es el objeto de esos medios), pero falta indagar en el engranaje que conecta a estas dos esferas: la narración.

Es evidente que una buena parte de la cosmovisión del ser humano consta de sentimientos estéticos. La vivencia de estos sentimientos no se reduce a simples juicios de gusto, sino que se vive 
persiguiendo estos sentimientos. No es sorpresa que las historias narradas en películas industrializadas recauden millones cada año. Desde las poesías homéricas hasta los comics del siglo pasado han provisto al humano de héroes a los cuales seguir, mundos sobre los cuales imaginar e historias que contar. Es característico del ser humano el contar historias.

La narración no se queda en el reino del mito o de la ficción, las historias también se pueden contar sobre pilares de realidad (digo, que es una leyenda sino esto). A algo tan humano, tarde o temprano, se le iba a encontrar alguna forma de instrumentalizarse. Ante esta realidad es pertinente preguntarnos ¿cómo es que los grupos y partidos políticos se presentan a los individuos? ¿cómo justifican su causa? Por medio del discurso.

El discurso es el eslabón entre representante y representado. Este mecanismo tiene la característica de ser unidireccional, es decir, que va del representante al representado. El discurso en estos tiempos no se da en foros, no se va a la plaza para escuchar al representante, sino que se manifiesta en un espacio virtual fuertemente habitado por los medios de comunicación. El discurso se manifiesta no solo por medio de eslóganes o publicidades tediosas, sino que también se manifiesta en todo un proceso casi que literario, uno narrativo ¿a qué me refiero con esto? Veamos: el medio de comunicación ¿qué es lo que comunica?, ¿información? Más que eso: narraciones.

La narración es, ante todo, una estructura expresiva, es una forma de contar sucesos. Aristóteles enlazara la narración con la naturaleza mimética del ser humano, argumentando que se hace poesía (entiéndase narración) imitando la realidad: “La epopeya y la tragedia, como también la comedia y la poesía ditirámbica y gran parte de la aulética, hablando en general, son imitaciones de la vida" (Aristóteles, 1982b, p. 349)

Lo peculiar de la narración es que se reviste de sentimientos estéticos, así como de una tesis de fondo que dota de sentido a la narración. Los grandes literatos caracterizan su tesis en forma de personajes y las relaciones entre ellos. Se cuenta una historia en los ojos de algún personaje, se narran sus luchas, sus logros, sus aspiraciones. Todo esto siempre desde una categoría estética: lo bello, lo sublime, lo cómico, lo trágico, lo repugnante, lo asombroso, lo bravo, etc. 
Es bajo estas categorías que el espectador se puede relacionar con sus personajes. Un personaje valiente, humilde y determinado inspira al espectador empatía, apoyo en su viaje. Contrario al personaje grotesco, vulgar o malicioso que empuja al espectador a repudiar sus acciones. Aristóteles diría:

Puesto que los seres humanos son objeto de imitación son necesariamente nobles o innobles -ya que se puede decir que los dos únicos criterios sobre los cuales se funda la diversidad de los caracteres son estos y que los hombres, en cuanto a su carácter, difieren por la virtud o por el vicio-, los seres humanos serán mejores que nosotros, peores o iguales. (Aristóteles, 1982b, p. 351).

A un personaje se le da protagonismo cuando se da a entender que la narrativa tiene como fin a ese personaje. Sin embargo, las narraciones van más allá de los personajes. En las narraciones se cuentan más cosas que simples biografías, sino también sucesos, contextos y pasados que explican el carácter de los actores. Estas cosas, los sucesos, personajes, lugares, artefactos y poco más son aquello a lo que denominamos el mundo de la historia. Aristóteles llamará a esto la unidad de la acción y la fábula.

Para constituir la unidad de una fábula no basta como creen algunos en que ella se desenvuelva alrededor de un personaje único, muchas más aun, innumerables cosas pueden sucederle a una persona sin que, no obstante, algunas de ellas constituyan unidad; así también, las acciones de una persona pueden ser muchas sin que por ello resulta una acción única. (Aristóteles, 1982b, p. 364).

Continua:

Así como en las otras artes de imitación, la imitación es una si uno es su objeto. Así también la fábula, puesto que se imita una acción, debe imitar una que sea única, esto es, capaz de construir un todo completo. (Aristóteles, 1982b, p. 365). 
Ruiz ya señaló esto, dirá respecto a los discursos electorales o políticos:

Se trata de discursos en los que hay diferentes formas discursivas que remiten a la información, la explicación, la argumentación, la conminación, la descripción, la narración, etc., pero en los que se identifica una línea narrativa que da coherencia y sentido al discurso en un nivel global. En estos casos, no hay necesariamente una sucesión lineal y temporalizada de acontecimientos, figurativización de los personajes y las escenas, etc. Por el contrario, pueden aparecer personajes con alto nivel de abstracción, como la patria o la libertad, y las líneas narrativas se cruzan y entrecruzan de manera fragmentada y compleja. (Ruiz, 2019, p. 27).

La forma en la que el artista expresa su cosmovisión en una narración es por medio de sus personajes y el mundo en donde estos se desarrollan. La historia de un personaje suele condensar una acción que da unidad y sentido a la historia contada.

Los medios de comunicación también pueden ser artistas y de hecho lo son. Se asume que los medios de comunicación transmiten información que es concorde con la realidad, no es descabellado decir que pretenden mostrar la realidad del mundo en el que vivimos por medio de noticiero, canales de opinión, documentales, reportajes etc.

¿A qué me refiero con la realidad o realidades que presentan estos medios? Aquellos sucesos (sociales, culturales, científicos) a los cuales el espectador no puede tener acceso directo y que contribuye a la formación de la idea de mundo en el que se vive o, en jerga orteguiana, circunstancia. Al estado de la sociedad, sus carencias, sus glorias, sus desafíos; agrupaciones de personas, su identidad, sus valores, sus luchas; el estado de los mercados, sus participantes, sus crisis, sus causas. La idea aristotélica del arte como imitación de la vida quizás haya caído en desuso en muchas formas de arte, pero en el caso de las narraciones preferidas de los medios de comunicación, considero que no solo se mantiene, sino que va más allá. El noticiero no imita a la vida, el noticiero presenta la vida.

Esta similitud en cuanto a la estructura de la narración ya ha sido estudiada. Ruiz dará cuenta de que: 
En definitiva, un discurso electoral siempre, en un nivel subyacente, da cuenta de una historia, entendida como un conjunto secuencial de transformaciones de algún tipo de sujeto, situación, etc. Transformaciones acontecidas que se explican o por acontecer y que se anuncian o se predicen, etc. (2019, p. 31).

Concluirá que los discursos electorales, así como de los movimientos sociales, se sirven de un tipo específico de narración llamada involucrativa, de ellos dirá que:

Los marcos que se desarrollan en los discursos de los movimientos sociales se organizan claramente con una estructura análoga a las narraciones involucrativas y sus contenidos y sus funciones son semejantes a los discursos electorales. En ambos casos se apela a la involucración de los ciudadanos en una acción colectiva con objetivos comunes y que se desarrollan en un escenario público en donde confluyen cuestiones sociales económicas, culturales o políticas. (2019, p. 31).

Al ser una narración involucrativa, se invita al espectador a participar en el desarrollo de la narración. Como ya se dijo, la peculiaridad de esta narración es que se sitúa en la realidad, en este caso, el mundo de la narración y el mundo real son una y la misma cosa. Cuando se le invita, por medio de la exposición de información específica, al ciudadano a ejercer una acción (votar o salir a marchar) se le tiene que dar una justificación en forma de un conflicto por resolverse.

Los medios tienen el poder de elegir los conflictos que se quedarán en la opinión pública. Esto los dota de un poder sutil: el poder de elegir cuales historias contar y cuales ignorar. Esto, en consecuencia, otorga el poder de influenciar las cosmovisiones de los individuos. Esto se manifiesta en las realidades concretas que comunican, transformándolas en el mundo de la narración en donde ciertos actores se desarrollarán; toman personas, grupos o pueblos enteros y los transforman en protagonistas o villanos, dotándolos de virtudes o vicios; toman las relaciones entre el mundo manufacturado, sus personajes, inclusive al propio narrador y lo transforman en la historia que ha de dotar de sentido a tal mundo. 
Tal cautelosa selección genera sentimientos estéticos en el espectador que inevitablemente lo motivarán a apoyar a los protagonistas y despreciar a los villanos, consecuentemente propiciando una aceptación de las tesis que manifestadas en dichos personajes. Dicho en clave aristotélica, las realidades se presentan como tragedias o comedias: "Esta es justamente la diferencia que existe entre la tragedia y la comedia: La una tiende a representar a los hombres mejores de lo que son y la otra, peores" (Aristóteles, 1982b, p. 351).

Los medios de comunicación, ya sea en forma de noticieros, foros de opinión, redes sociales o cualquier medio similar, alimentan a su espectador con estas narraciones. $Y$ no es sorpresa que sea la forma favorita de comunicar hechos, pues reviste de sentimientos estéticos la interpretación de la realidad, sentimientos que tienen gran peso a la hora de tomar decisiones políticas como ya se ha demostrado (Westen, 2007).

El representante se beneficia enormemente de que su causa sea más que una simple cosmovisión, sino que sea protagónica, verosímil y necesaria. Como he dicho antes, en la narración se asume un mundo en el que los personajes se desarrollan. El artista manufactura el mundo y le dota de sentido con la historia que inevitablemente se ha contar.

Los medios de comunicación tienen el poder de construir mundos en los cuales los representantes se han de desenvolver. No se narran simples hechos en los noticieros, se narran los hechos que caben dentro de la narración que da sentido a todas las demás narraciones. Ruiz llamará a estas "Narraciones maestras" (2019, p. 30). Dichas narraciones dotan de verosimilitud al discurso político que legitima o deslegitima un curso de acción.

Al artista no le reprochamos el revestir la realidad de estética, pues es necesaria para su expresión artística. Suele quedar claro que, lo que sea que represente el artista, no tiene por qué representar a nadie. Dicha realización no sucede con los medios de comunicación. Volviendo la vista a Aristóteles, vemos que la diferencia que hace entre historia y poesía nos permite vislumbrar mejor este hecho:

De lo que se ha dicho anteriormente resulta claro también que el oficio del poeta no es describir realmente las cosas acaecidas, sino aquellas que pueden suceder, esto 
es, cosas que son posibles según las leyes de la semejanza y la necesidad. Efectivamente el historiador y el poeta no se diferencian porque uno escriba en verso y el otro en prosa, la historia de Heródoto, por ejemplo, podría muy bien ser puesta en versos y de esta manera no sería menos historia de lo que es. (Aristóteles, 1982b, p. 365).

\section{Continua:}

La verdadera diferencia es esta: el historiador describe realmente hechos acaecidos, y el poeta, hechos que pueden acaecer. Por esto la poesía es más filosófica y elevada que la historia: la poesía más bien tiende a representar lo universal, la historia lo particular. De lo universal podemos dar una idea de este modo: un individuo de tal o cual naturaleza tiene que hacer o decir cosas de tal o cual naturaleza según las leyes de la verosimilitud o de la necesidad. (Aristóteles, 1982b, p. 365).

La diferencia entre el mundo del artista y el del comunicador es que uno se presenta como creación de un autor, mientras que el otro se presenta como el mundo real. Para este la línea entre historia y poesía es harto delgada.

Aplicando estos conceptos a los estudios de Bostrom (1983) Diríamos que el fin de la narración política manifestada en los medios de comunicación es el de persuadir (moldear, cambiar o reforzar respuestas) a los votantes de cierto curso de acción. Los medios de comunicación presentan el ambiente (mundo de la narración) por medio de noticieros, notas, reportajes, documentales, etc. Al ser estos los traductores del ambiente (mundo real) con un alto grado de credibilidad, el votante promedio toma a estos medios como fuente de información confiable y forma su opinión basándose en los análisis y evidencias presentadas por estos medios, allende su veracidad. 
Como dije antes, el ser humano necesariamente interpreta su realidad pues las cosas no hablan por sí mismas. Estas narraciones pesan en las posibles interpretaciones de los ciudadanos y por extensión, en su identidad (como ya se exploró de mano de Castell en el primer capítulo). Este es el mecanismo que los representantes utilizan para generar simpatizantes.

El problema no es per se la existencia de las narraciones, sino su pretensión de realidad. Un individuo puede leer una novela y decidir concordar o rechazar sus propuestas, pues esa novela es producto de un autor y el lector está consciente de esto. Sin embargo, cuando un medio de comunicación presenta la narración como realidad (la poesía como historia) ¿puede uno rechazar la propuesta? De ser así el individuo correría el riesgo de sostener creencias falsas.

Esta construcción de la narración se puede evidenciar con la selección de crímenes que se han de mostrar al público, señalando al grupo al que el criminal pertenece, alimentando la noción de protagonismo-antagonismo; la selección de qué protestas mostrar y cuales ignorar, expresando al espectador cuales son justas y valerosas, cuales ruines y perversas; escrudiñando cada palabra de determinados representantes, mostrando cuales son perversos e inmorales, cuales mesurados y conscientes; seleccionar qué documentales producir, mostrando qué grupos hemos de apoyar, a cuales despreciar.

Siguiendo a Ruiz (2019): en esta estructura narrativa se ven impresos esquemas interpretativos sobre la realidad (marcos de referencia). Por un lado, se muestran problemáticas sociales, sus causas y sus culpables (marco de diagnóstico). Por otro, se muestra quien o quienes luchan o deberían luchar por resolver tales problemáticas, así como los cursos de acción que han de tomar (marcos de pronóstico).

Esto tiene una implicación importante:

La articulación de marcos de diagnóstico y marcos de pronóstico genera el esquema de un relato. Un relato que, como toda estructura narrativa estándar, comienza con una situación problemática que hay que resolver y con una distribución de roles sobre culpables, héroes, antagonistas, etc. También se señalan los objetivos finales y las acciones que el 
sujeto colectivo protagonista desarrollará para conseguir cumplir la misión que se le ha adjudicado. (2019, p. 32).

Es cierto que los medios construyen realidad pues es de ellos de donde el ciudadano común se alimenta para construir la cosmovisión de un mundo tan complejo. Esta es claramente una relación de poder en la medida en que estas narraciones moldean la opinión pública, elemento sagrado en una democracia. Creo que no hace falta citar ejemplos de esta técnica. La propaganda de los estados autoritarios del siglo XX es evidencia suficiente de cómo se puede manipular a una nación entera para creer una narración: la lucha capitalismo-comunismo y el antagonismo ario-judío son amargos recuerdos.

Esta es la obra maestra de la manipulación mediática, la narración. No es sorpresa que los medios de comunicación apoyen a ciertos partidos, revelen información comprometedora de sus adversarios, sostengan lo justo o injusto de un acto, hablen sobre el carácter de algún representante, resalten sus virtudes y enmarquen su discurso en la gran historia que cuidadosamente han escrito durante años. La narración no es exclusiva de los medios, los grupos políticos que se muestran como los oprimidos (protagonistas) y muestran a otras entidades como los opresores (villanos) tienden a caer en narraciones.

El problema con esta forma de contar sucesos es epistemológico. Las narraciones siempre tienen un fin. En clave aristotélica, no se persigue la verdad, sino la verosimilitud. Aristóteles dirá:

Si un poeta tuviese que crear sobre hechos realmente sucedidos, por esto no sería menos poeta; si bien entre los hechos realmente sucedidos nada impide tampoco que existan algunos de tal naturaleza como para poderlos concebir como efectivamente sucedieron, sino como hubiera sido posible y verosímil que sucedieran. Es justamente bajo este aspecto, el de su posibilidad y verosimilitud que quien los trata no es su historiador, sino su poeta. (Aristóteles, 1982b, p. 366).

Los grandes literatos cuentan historias en mundos que no existen para comunicarle algo al lector, así como los grupos políticos y medios de comunicación envían un mensaje por medio de sus 
narraciones ¿quién no quiere sentirse representado por quien lucha por el lado correcto de la historia? Estos sentimientos estéticos inevitablemente motivaran al espectador a elegir a tales representantes cuya historia se está contando.

La diferencia entre el literato y el medio de comunicación es la simple honestidad. El literato crea sus mundos o los toma prestados de la realidad, el medio de comunicación sostendrá que el mundo de la narración es la realidad y que las conclusiones morales y estéticas que se derivan de esa historia son tan reales como el mundo en que vivimos. Uno pretende mostrar, otro demostrar. El espectador es consciente de esto cuando lee un libro, que las tesis derivadas de la historia o los fines a los que tiende son producto del autor, pero no es consciente de que las conclusiones derivadas de un medio de comunicación son también producto de los medios, no de la realidad.

\section{Un voto de desconfianza}

Los medios de comunicación tienen un poder sutil pero significativo en el juego político, pues ellos tienen el oligopolio de las narraciones que inevitablemente moldean las cosmovisiones de espectadores incautos. ¿Qué hacer ante esta quimera?

El poder de los medios solo es posible gracias a la confianza o credibilidad que se tiene en ellos. Si bien, es cierto que, en ocasiones, la información expresada en los medios de comunicación puede ser verdadera y desinteresada, no es menos cierto que pueda no serlo. Toda verdad que lancen los medios ha de ser considerada, cuando mucho, provisional. Es sano ser escéptico ante la realidad, aunque no sea lo más cómodo. Conocer la forma en la que se construye una narración da armas al individuo para encontrar narraciones en los discursos, como quien aprende un arte marcial para poder defenderse de otros.

Ciertamente una vida democrática necesita individuos suficientemente escépticos como para dudar de sus fuentes, pero suficientemente altruistas como para querer un bien común. Este bien ha de lograrse depurando las ideas, contrastando, no descartando. Al final, como dirá Rousseau: "El pueblo quiere indefectiblemente su bien, pero no siempre lo comprende. Jamás se 
corrompe al pueblo, a menudo se le engaña y es entonces cuando parece querer el mal." (Rousseau, 1985, p. 58).

\section{Referencias}

Aristóteles. (1982a). Política (Decimoquinta ed.). (L. Segura, Trad.) Ciudad de México: Cumbre. Aristóteles. (1982b). Poética (Decimoquinta ed.). (L. Segura, Trad.) Ciudad de México: Cumbre. Bostrom, R. N. (1983). Persuasion. Englewood cliffs: Pretince-Hall.

Caplan, B. D. (2006). The Myth of the Rational Voter. Why Democracies Choose Bad Policies. Princeton: Princeton University press.

Castells, M. (1998). La era de la información: economía, sociedad y cultura. Volumen I: La socieda red (Segunda ed.). (C. Martínez, Trad.) Madrid: Alianza.

Castells, M. (2001). La era de la información: economía, sociedad y cultura. Volumen II: El poder de la identidad (Tercera ed.). (C. Martínez, Trad.) Ciudad de México: Siglo veintiuno.

Horkheimer, M., \& Adorno, T. W. (1998). Dialéctica de la ilustración (Tercera ed.). (J. J. Sánchez, Trad.) Madrid: Trotta.

McLuhan, M. (1994). Comprender los medios de comunicación: las extensiones del ser humano. (P. Ducher, Trad.) Barcelona: Paidós.

Ortega, J. (1984). Historia como sistema. Madrid, España: Sarpe.

Ortega, J. (2012). La rebelión de las masas. Madrid, España: Gredos.

Postman, N. (2001). Divertirse hasta morir: el discurso en la era del "show business" (Segunda ed.).

(E. Odell, Trad.) Barcelona: Ediciones de la tempestad.

Rousseau, J. (1985). El contrato social. (E. Azcoaga, Trad.) Madrid, España: Sarpe.

Ruiz, F. (2019). La construcción del relato político: crear historias para ganar votos. Barcelona: Universidad Autónoma de Barcelona.

Sartori, G. (1998). Homo videns: La sociedad teledirigida. (A. Díaz, Trad.) Buenos Aires: Taurus. Westen, D. (2007). The political brain. Nueva York: Public affairs.. 